Никита Большаков

\title{
КОХЛЕАРНАЯ ИМПЛАНТАЦИЯ: МЕЖДУ МЕДИКАЛИЗАЦИЕЙ И КУЛЬТУРОЙ ГЛУХИХ
}

\section{Mauldin L. (2016) Made to Hear: Cochlear Implants and Raising Deaf Children. Minneapolis: University of Minnesota Press. 232 p. ISBN 978-0-8166-9725-0}

\section{DOI: $10.17323 / 727-0634-2021-19-4-744-750$}

Последние десятилетия XX в. оказались переломными для социализации и обучения глухих детей. Появление и последующее внедрение кохлеарной имплантации (КИ) в общую медицинскую практику в 1980-е гг. на Западе (Ramsden 2013) и в 1990-е в России (Таварткиладзе 2017) привело, говоря в медицинских терминах, к пересмотру основных подходов к реабилитации людей с нарушениями слуха. В то же время совпав с периодом борьбы людей с инвалидностью за свои права, ростом интереса исследователей к жестовым языкам и последующего признания жестовых языков в разных странах в качестве естественного средства общения, становления собственной идентичности глухих, КИ не получила однозначной поддержки внутри сообщества до сих пор. Именно этой амбивалентной природе КИ и посвящена книга «Созданы, чтобы слышать: кохлеарные импланты и воспитание глухих детей» американской исследовательницы Лоры Молдин.

В основе книги лежит полугодовое мультиметодное этнографическое исследование, включающее в себя интервью с родителями имплантированных детей и специалистами в школах и клинике, профилирующийся на раннем выявлении глухоты и КИ, а также наблюдение в ходе различных медицинских и образовательных мероприятий и родительских групп поддержки. Интерес Молдин лежит на стыке исследований инвалидности и технологий, поэтому выбор именно КИ в качестве предмета изучения выглядит логичным развитием её исследовательской карьеры. Имея за плечами опыт обучения на программе Deaf Studies в Галлодетском университете, единственном в мире университете для глухих, в котором обучение ведется на жестовом языке, работы в качестве приглашенного исследователя в центре Deaf Studies университета Бристоля, а также преподавания в Национальном техническом институте для глухих Рочестерского института технологий, Молдин в своем исследовании развенчивает некоторые мифы, связанные с имплантацией, стараясь при этом не уходить полностью в «глухую критику» (Deaf critique).

\footnotetext{
Никита Викторович Большаков- к.социол.н., ст. преподаватель, кафедра методов сбора и анализа социологической информации; ст.н.с., Международная лаборатория исследований социальной интеграции, Национальный исследовательский университет «Высшая школа экономики», Москва, Россия; куратор программ доступности и инклюзии, Музей криптографии, Москва, Россия. Электронная почта: nbolshakov@hse.ru
} 
Согласно современным определениям, КИ понимается как комплексная система мероприятий (Сатаева 2008), включающая в себя не только хирургическую операцию, но и педагогическую работу, а также, на что обращает внимание Молдин, активное участие близкого окружения глухого ребенка в его интеграции в слышащее общество. В соответствии с этим подходом, книга состоит из пяти глав, посвященных последовательным этапам КИ: идентификация (identification), инициация вмешательства (initiation of intervention), подготовка (candidacy), операция (surgery) и длительный уход (long-term follow-up care).

Первая глава посвящена рассмотрению институциальных процессов внутри клиники, призванных направлять опыт семьи глухого ребенкапредупреждающим структурам (anticipatory structures), как называет их сама Молдин. К числу таких структур она относит использование специальной лексики, особые практики построения доверительных отношений между специалистами-медиками и родителями, которые необходимы для снижения родительского сопротивления медицинскому вмешательству и возвращения их в клинику в случае условно «неудачного» первого теста-если ребенок не реагирует на звуковые сигналы.

Молдин как этнограф уделяет большое внимание деталям: чем занимались Кэрол, или Джейн, матери имплантированных детей, когда она приехала к ним на интервью, как Нэнси и Гретхен пришли к созданию групп поддержки для родителей. Абсолютное большинство героев книги - женщины-матери - именно на них, как правило, ложится ответственность за воспитание имплантированного ребенка. Для описания опыта этих женщин Молдин использует понятие научного материнства (scientific motherhood), так как они не имеют спонтанного выработанного самостоятельно понимания глухоты собственного ребенка, а сразу оказываются погружены в доминирующий в клинике неврологический дискурс глухоты, который использует научный язык для обоснования, почему глухоту необходимо лечить.

Вторая глава фокусируется как раз на рассмотрении механизмов, которые используются медицинскими специалистами для вовлечения родителей в этот дискурс. Главным страхом родителей, у которых рождается глухой ребенок, является опасение, что ребёнок навсегда останется исключенным из общества, и специалисты программ раннего выявления глухоты, которые «продолжают совершать чудеса каждый день» (Р. 58), то есть борются с глухотой, предлагают родителям инструменты для снижения этого беспокойства. Молдин говорит о формировании КИ-культуры (CI-culture), в рамках которой жестовый язык считается компенсаторным инструментом, глухота- злом, а имплантация- единственным шансом дать ребенку возможность «нормального» развития. В то же время на практике хирургическая операция не становится панацеей, а успешная КИ по большей части является актом социальной и родительской ответственности (Tucker 1998). Это требует 
серьезной работы самих родителей, которые, усвоив что КИ- это чудо и спасение, часто оказываются не подготовлены к этой работе.

При этом потенциальная успешность кандидатов на имплантацию оценивается не только с помощью медицинских, но и во многом социальных критериев, что Молдин раскрывает в третьей главе. Хотя в США нет четких данных о социально-экономическом положении семей- и здесь ситуация оказывается похожа на российскую с непрозрачностью выстроенной системы статистики инвалидности (Бурдяк и др. 2017) - к числу успешных кандидатов чаще относят белых и азиатов (Belzner, Seal 2009), а также в целом представителей среднего класса, т.е. «нормальных родителей» (Р. 105), что определяется во многом представлениями аудиологов об идеальном кандидате, родители которого должны отлично владеть английским языком и принимать потерю слуха ребенка.

Молдин объясняет это в следующей главе тем, что появление КИ способствовало переопределению глухоты из сенсорного нарушения в нейрофизиологическое, поэтому специалисты по КИ говорят о необходимости тренировать мозг (ответственность, которая ложится на родителей) и приоритете устного языка, который, по их мнению, в отличие от жестового позволяет мозгу нормально развиваться. В то же время сами родители сопротивляются этому подходу и используют жестовый язык, потому что для них зачастую он становится единственным эффективным способом коммуникации с ребенком. Дискуссия о роли жестового языка в социализации и обучении детей с КИ вообще играет важную роль в жизни родителей, медиков, педагогов. В то время как отоларингологи и аудиологи отрицают жестовый язык, вся остальная литература говорит о пользе его использования и о появлении синергетического эффекта от применения билингвистических методик обучения детей. О пользе развития билингвистических подходов в обучении детей с КИ говорят и представители российского родительского сообщества (Маллабиу, Бойцева 2017), хотя они и не ратуют исключительно за жестовый язык, а говорят именно о грамотном совмещении визуальных и устных языков.

В этом контексте работа Молдин затрагивает еще одну важную дискуссию- об отношениях исследований глухоты (Deaf studies или Deaf critique) и более широкого направления - исследований инвалидности (Disability studies), которые находятся во многом в оппозиции друг к другу. Исследователи инвалидности, как правило, включают глухих и слабослышащих в свою область интересов, тогда как сами глухие обычно отвергают ассоциации с инвалидностью за счет своих культурных особенностей. Одним из примеров противостояния движений инвалидности и глухоты является реакция глухих на введение инклюзивного образования (Shapiro 1994), результатом развития которого стало снижение финансирования специальных школ для глухих, являющихся «краеугольным камнем» культуры глухих и глухой идентичности, что вызвало недовольство со стороны представителей сообщества. Аналогичные процессы наблюдались и в России. 
В рамках дисциплины Deaf studies глухота перестает рассматриваться как инвалидность, а, помещаясь в культурный дискурс, интерпретируется как особенность или даже сила (Jankowski 1997) глухих и слабослышащих, способствующая их самоопределению и идентификации. Вопросы идентичности имплантированных глухих детей Молдин раскрывает в других своих работах (Mauldin 2019).

В последней главе обсуждается дальнейшая жизнь имплантированных детей. Образование глухих и слабослышащих изменилось после появления КИ, а разговор о развитии языковых и интеллектуальных способностей имплантированных детей приводит к дальнейшей интервенции медицинских взглядов во все сферы, включая образование, определяя тем самым ежедневную жизнь семей. В итоге основной текст Молдин завершает выводом о том, что задачей как самой КИ, так и последующей реабилитации, в том числе образовательной, является не столько социализация глухих детей, сколько избавление от глухоты, как в медицинском, так и социальном или культурном смыслах, особенно в среде белых представителей среднего класса.

В целом несмотря на то, что книга критиковалась за фактические неточности (Ammerman 2017), а некоторые базовые предпосылки (например, opганизация системы раннего выявления глухоты, медицинской помощи, поддержки родителей) с трудом применимы к российской действительности, Made to Hear обращает внимание на амбивалентную природу как медикализации в целом, так и КИ в частности. КИ-культура, с одной стороны, обещает родителям чудесное исцеление, но с другой- слабо готовит их к тем трудностям, с которыми им приходится столкнуться после операции. Это приводит к росту озабоченности и формированию низовых форм поддержки, новых сообществ. Хотя «глухая критика» зачастую оценивается как идеологизированная и агитирующая за жестовый язык и культуру глухих, результаты исследования Молдин демонстрируют, что медикализированные процессы имплантации также оказываются глубоко идеологизированы, а запрет на использование жестового языка является скорее политическим, нежели рациональным. В этом смысле оба подхода к глухоте обладают своими ограничениями, а противопоставление КИ-культуры и культуры глухих во многом является искусственным. Этот вывод очень важен в российском контексте, где использование жестового языка в образовании и социализации глухих и слабослышащих до сих пор вызывает дискуссии, а полноценная реабилитация после операции по КИ доступна не всем детям (Люкина и др. 2017).

\section{Список источников}

Бурдяк А. Я., Васин С. А., Макаринцева А. О., Хасанова Р.Р., Цацура Е. А. (2017) Инвалидность и сочиальное положение инвалидов в России. М.: Дело. 
Люкина А.С., Красильникова О. А., Ильюшина С. В. (2017) Коммуникативные умения детей с КИ, не прошедших или не завершивших реабилитации. Результаты эмпирического исследования. Альманах Института коррекиионной педагогики PAO, (30): 143-160.

Маллабиу А., Бойцева 3. (ред.) (2017) Билингвизм: роль жестового языка в языковом и когнитивном развитии детей с нарушенным слухом. СПб.: Реноме.

Сатаева А.И. (2008) Кохлеарная имплантация как средство помощи глухим детям. Воспитание и обучение детей с нарушениями развития, (1): 55-63.

Таварткиладзе Г.А. (2017) История кохлеарной имплантации. Альманах Института коррекиионной педагогики РАО, (30): 10-26.

Ammerman S. (2017) Made to Hear. The Journal of Deaf Studies and Deaf Education, 22 (2): 254 .

Belzner K., Seal B. (2009) Children with Cochlear Implants: A Review of Demographics and Communication Outcomes. American Annals of the Deaf, 154 (3):311-33.

Jankowski K. A. (1997) Deaf Empowerment: Emergence, Struggle, and Rhetoric. Washington: Gallaudet University Press.

Mauldin L. (2019) Lessons Learned: How Studying Cochlear Implantation Reveals the Context in which d/Deaf Identities are Formed. In: I. W. Leigh and C.A. O'Brien (eds.) Deaf Identities: Exploring New Frontiers. Oxford: Oxford University Press: 96-119.

Ramsden R. T. (2013) History of the Cochlear Implantation. Cochlear Implants International, 14 (4):3-5.

Shapiro J.P. (1994) No Pity: People with Disabilities Forging a New Civil Rights Movement. New York: Broadway Books.

Tucker B.P. (1998) Deaf Culture, Cochlear Implants, and Elective Disability. Hastings Center Report, 28 (4): 6-14. 


\title{
COCHLEAR IMPLANTATION: BETWEEN MEDICALIZATION AND DEAF CULTURE
}

\author{
Mauldin L. (2016) Made to Hear: Cochlear Implants and Raising \\ Deaf Children. Minneapolis: University of Minnesota Press. 2015 \\ pp. ISBN 978-0-8166-9725-0
}

\author{
DOI: $10.17323 / 727-0634-2021-19-4-744-750$
}

\section{References}

Ammerman S. (2017) Made to Hear. The Journal of Deaf Studies and Deaf Education, 22 (2): 254 .

Belzner K., Seal B. (2009) Children with Cochlear Implants: A Review of Demographics and Communication Outcomes. American Annals of the Deaf, 154 (3):311-33.

Burdyak A. Ya., Vasin S. A., Makarintseva A. O., Khasanova R. R., Tsatsura Ye.A. (2017) Invalidnost' $i$ sotsial 'noe polozhenie invalidov v Rossii [Disability and Social Status of Disabled People in Russia]. Moscow: Delo.

Jankowski K. A. (1997) Deaf Empowerment: Emergence, Struggle, and Rhetoric. Washington: Gallaudet University Press.

Lyukina A. S., Krasil'nikova O.A., Il'yushina S.V. (2017) Kommunikativnye umeniya detey s KI, ne proshedshikh ili ne zavershivshikh reabilitatsii. Rezul'taty empiricheskogo issledovaniya. [Communication skills of Children with CI Who Have not Completed or Have not Rehabilitation. The Results of the Empirical Study]. Al'manakh Instituta korrektsionnoy pedagogiki RAO [Almanac of the Institute of Special Education of the Russian Academy of Education], (30): 143-160.

Mallabiu A., Boytseva Z. (eds.) (2017) Bilingvizm: rol' zhestovogo yazyka v yazykovom i kognitivnom razvitii detey s narushennym slukhom [Bilingualism: The Role of Sign Language in the Language and Cognitive Development of Children with Hearing Impairments]. St. Petersburg: Renome.

Mauldin L. (2019) Lessons Learned: How Studying Cochlear Implantation Reveals the Context in which d/Deaf Identities are Formed. In: I. W. Leigh and C.A. O'Brien (eds.) Deaf Identities: Exploring New Frontiers. Oxford: Oxford University Press: 96-119.

Ramsden R. T. (2013) History of the Cochlear Implantation. Cochlear Implants International, 14 (4):3-5.

Nikita Bolshakov- Cand. Sci. (Sociol.), Senior Lecturer, Department of Sociological Research Methods; Senior Research Fellow, International Laboratory for Social Integration Research, National Research University Higher School of Economics, Moscow, Russian Federation; Curator of Accessibility and Inclusion Programs, Cryptography Museum, Moscow, Russia. Email: nbolshakov@hse.ru 
Sataeva A. I. (2008) Kokhlearnaya implantatsiya kak sredstvo pomoshchi glukhim detyam [Cochlear Implantation as a Means of Helping Deaf Children]. Vospitanie i obuchenie detey s narusheniyami razvitiya [Education and Training of Children with Developmental Disorders], (1): 55-63.

Shapiro J. P. (1994) No Pity: People with Disabilities Forging a New Civil Rights Movement. New York: Broadway Books.

Tavartkiladze G. A. (2017) Istoriya kokhlearnoy implantatsii [History of Cochlear Implantation]. Al'manakh Instituta korrektsionnoy pedagogiki RAO [Almanac of the Institute of Special Education of the Russian Academy of Education], (30): 10-26.

Tucker B. P. (1998) Deaf Culture, Cochlear Implants, and Elective Disability. Hastings Center Report, 28 (4): 6-14. 